Sabah A Ismail

BDS, MSc (Asst. Prof.)

Nawfal A Zakaria

BDS, MSc (Asst. Prof.)

Manal A Sultan

BDS, MSc (Lec.)

\section{The Effect of Two Endodontic Rotary Systems in Root Canal Preparation on Apical Microleakage}

Dept of Conservative Dentistry

College of Dentistry, University of Mosul

Dept of Conservative Dentistry

College of Dentistry, University of Mosul

Dept of Conservative Dentistry

College of Dentistry, University of Mosul

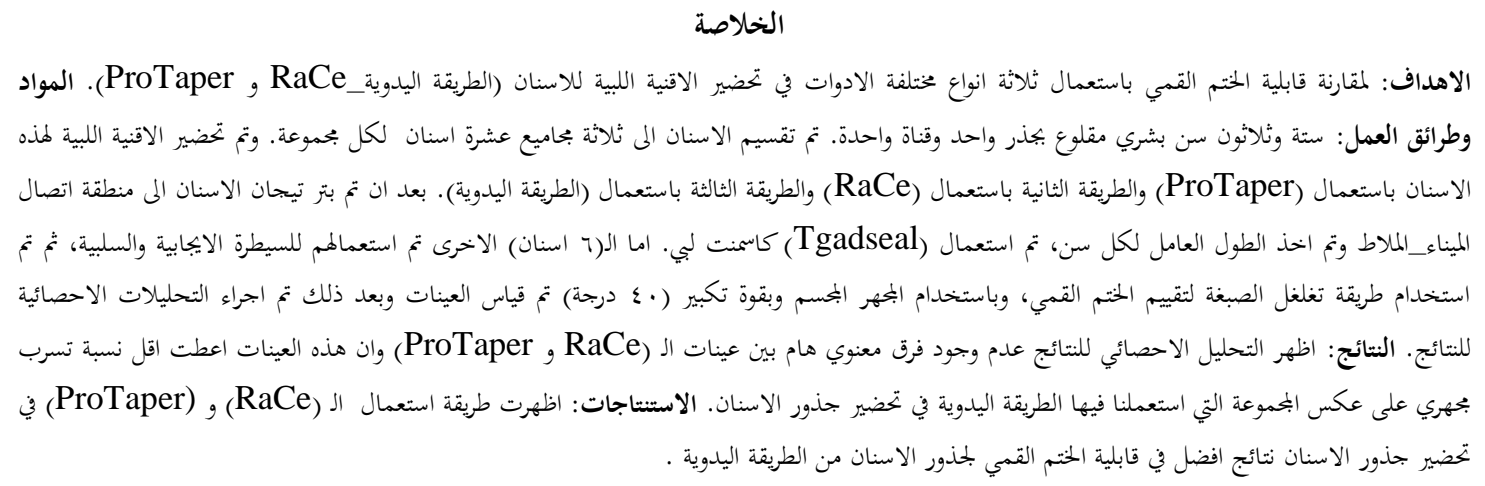

ABSTRACT
Aims: the aim of this in vitro study was to evaluate the apical sealing ability where the canals are prepaid by two rotary NiTi systems . Materials and Methods: Thirty-six extracted human teeth with single root cut there crowns at the cemento-enamel junction CEG. The working length was determined for each tooth. The teeth were divided in to (3)groups ten of each. Group I the teeth were instrumented with ProTaper NiTi then the teeth obturated with matched-taper single cone. Group II of teeth were instrumented with RaCe NiTi rotary instrument and then obturated with matched-taper single cone. Group III were instrumented by hand instruments K-files and obturated by the lateral condensation techniques. Six teeth were divided as positive and negative control group three for each one . Tgadeseal was used as root canal sealer in this study. Adye penetration method was used to evaluate the apical seal using steromicroscope at 40X magnification. One-way analysis of variance and Duncan's test were used for statistical analysis. Results: The statistical analysis of the results demonstrated that there was no statistically significant difference in Microleakge between the two different rotary instrument each ProTaper and RaCe. While there was significant difference between the rotary instrument and the Hand instrument K-files. Conclusions: The use of the NiTi rotary instrument for root canal preparation showed the least apical microleakage, in compaired with hand instrument.

Keywords: Apical seal, rotary instrument, ProTaper and RaCe

Ismail SA, Zakaria NA, Sultan MA. The Effect of Two Endodontic Rotary Systems in Root Canal Preparation on Apical Microleakage. Al-Rafidain Dent J. 2013; 13(1): 37-43.

Received: 25/4/2011

Sent to Referees: $27 / 4 / 2011$

Accepted for Publication: 10/7/2011

\section{INTRODUCTION}

One of the main objectives of root canal preparation is to shape and clean the root canal system effectively whilst maintaining the original configuration without creating any iatrogenic event such as instrument fracture, external transportation, ledge, or perforation. ${ }^{(1)}$ However, in particular when used in severely curved ca- nals, traditional stainless steel instruments often fail to achieve the tapered root canal shapes needed for adequate cleaning and filling. ${ }^{(2-4)}$

Root canal microleakge is a complex subject because many variables may influence infiltration, filling techniques, physical and chemical properties of sealers and presence or absence of smear layers. The 
smear layer resulting from root canal instrumentation acts as a physical barrier interfering with adaptation and penetration of the sealer in to the dentinal tubules, which might contribute for microleakage occurrence. $^{(5)}$

Use of chemical active, adhesive root canal sealers may play an important rule in minimizing apical leakage. ${ }^{(6)}$

During the last decade, several new Nickel-Titanium (Ni-Ti) instruments for rotary endodontic treatment have extended the endodontic armamentarium. Even though the working safety of rotary instrument has been discussed in deferent ways, several investigation have shown the ability of some new rotary Ni-Ti systems to maintain the original root canal curvature well. ${ }^{(7-9)}$

In order to improve working safety, shorten preparation time and create a continuously tapered, conical flare of preparations advanced instrument designs with non cutting tips, radial lands, deferent cross-sections, superior resistance to torsional fracture and varying tapers have been developed. ${ }^{(10)}$

There are several series of investigations that have focused on deferent $\mathrm{Ni}-\mathrm{Ti}$ system using an identical design. ${ }^{(11,12)}$

The purpose of the present study was to evaluate the apical microleakge of root canal prepared by Pro-Taper (Dentsply Maillefer, Baillaigues, Switzerland) and RaCe (FKG Dentaire SA, La Chaux -deFonds, Switzerland) Ni-Ti instruments as well as manual technique.

\section{MATERIALS AND METHOD}

Thirty six human single rooted teeth were used, the teeth had mature apices and single-canal configuration the roots with open apices, cracks, and resorptive defect were excluded. The teeth were cleaned by the use of ultrasonic scaler and $\mathrm{NaOCl}$ $0.5 \%$ and polished. The crowns were removed at the cemento-enamel junction with diamond wheel saw(KG Sorensen SP, Brazil) under water coolant. The roots were accessed and to determined the working length, a size \#15 K-file (MAIN, INC. JAPAN) was inserted in to the canal until it was visible at the apical foramen. The working length of each canal was cal- culated to be $1 \mathrm{~mm}$ short of that position (from the apical foramen). All teeth divided into three groups 10 for each group and the remaining six teeth divided to two groups three negative control and three positive control.

Group I : Teeth prepare with ProTaper Ni-Ti rotary instrument to a size F3. A total of six instruments were used with contra-angle rotary hand piece (EndoMate DT, NSK, NAKANISHI, INC, JAPAN).

The speed of rotation was maintained at $250 \mathrm{rpm}$ and torque $3 \mathrm{Nm}$, using EDTA gel (Bio oinamica Quim E FramLTDA, Ibipora Parana Barsil) as a lubricant during instrumentation.

Two milliliters of $2.5 \%$ sodium hypochlorite solution were used for irrigation between each file size. ProTaper files were used in the following sequence, according to the manufacturer's recommendations:

1) The pulp chamber was filled with EDTA for lubrication and the S1 file was used enlarge the coronal twothirds of the canal.

2) The canal was irrigated using two milliliters of $2.5 \%$ sodium hypochlorite solution using hypodermic syringe. The needle inserted to $2 / 3$ of canal length. SX file was inserted into the canal until it encountered light resistance. Shaping with SX was continued with brushing motion until two -thirds of its cutting blades were below the orifice.

3) The canal was irrigated and size \#10 Kfile was used for recapitulation.

4) Shaping continued with the S1 file to the working length.

5) Then $S 2$ file was taken to the working length.

6) The F1 file was taken to the full working length and immediately with drawn.

7) The F2 file was taken to the full working length and immediately with drawn.

8) The F3 file was unserted to the full working length and immediately with drawn.

The teeth irrigated with $2.5 \%$ sodium hypochlorite and dried by paper point. Tgadseal root canal sealer (Technical and General LTD, London-United Kindom) was used as a sealer and the root canals 
were obturated using Matched-Taper Single-Cone (gutta perch for ProTaper, size F3, Dentsply Maillfer) technique.

Group II: $\mathrm{RaCe}$ instruments were used with rotary hands instrument (EndoMate DT, NSK, NAKISHI, INC). RaCe instruments were used in crown down manner using gentle brushing motion. Instruments were with drawn when resistance was felt and changed for the next instrument in the following sequence, according to the manufacture's recommendations:

1. The pulp chamber was filled with EDTA gel for lubrication and a 0.10 taper size 40 file was used to one-third of the working length.

2. The canal irrigated using two milliliters of $2.5 \%$ sodium hypochlorite solution and a 0.08 taper size 35 file was used to one-third to one half of the working length.

3. The canal was irrigated and a 0.06 taper size 30 file was used to one-half to two-third of the working length.

4. The canal irrigated and 0.04 taper size 25 file was used to two-third of the working length.

5. A 0.02 taper size 25 instrument was used to the full length of the canal.

6. The canal irrigated and a 0.02 taper size 30 instrument was used to the full length of the canal.

7. A 0.02 taper size 35 instrument was used to the full length of the canal.

Once the instrument had negotiated to the end of the canal and rotated freely, it was removed.

After irrigation and dryness of the canals. All teeth obturated by the use of matched-taper Single-cone(guttapercha for RaCe, FKG DENTAIRE Swiss Dental Produce) and also by the use of tgadsed root canal sealer.

Group III: Canals were prepared by crown down technique (manual technique) with early coronal flaring stainless steal Kfiles coronal flaring was done using GatesGlidden drills No. 4,3 and 2. The stepback technique was followed ${ }^{(13)}$.

Irrigated with $2.5 \%$ sodium hypochlorite solution and EDTA gel also between files during instrumentation, recapitulation with the $15 \# \mathrm{~K}$ file carried out to the working length.
Instrumentation with hand instrument was done until size 35 file. After the preparation procedure was complete, the teeth were irrigated with $2.5 \%$ sodium hypochlorite and dried. By the use of Taggdseal root canal seal and by the cold lateral condensation technique all the teeth were obturated.

After obturation of all teeth, the gutta percha was removed from orifice for $3 \mathrm{~mm}$ and sealed with Tetric-Ceram light cured composite resin.

All teeth were incubated at $37 \mathrm{C}^{\circ}$ $100 \%$ humidity for 7 days to allow the sealing materials to set completely. In the experimental groups all roots surfaces except the apical $2 \mathrm{~mm}$ were covered with two coats of nail polish. The remaining six teeth were use as positive and negative control groups.

The root canals were not obturated in the positive control group to allow maximum leakage. The root surfaces of these teeth were also coated with 2 layers of nail polish, except the apical $2 \mathrm{~mm}$. The teeth in the negative control group were obturated and sealed from the coronal portion by Tetric ceram, and from the apical portion by wax after it completely coated with two layers of nail polish to ensure that there was no leakage.

The experimental and control groups were each placed in 36 containers which were filled to identical levels with $2 \%$ methylene blue dye for three days. The teeth were rinsed with running water and dried.

Each roots were groved buccally and lingually with diamond wheel saw (KG Sorensen SP, Brazil ) under water coalant, ensuring that the root canal hilling was not penetrated, and then they were split into two halves by levering with a plaster knife.

The liner extent of dye penetration from the apical root ends was measured using a stereomicroscope (Motic, TAIWAN) at (X 40) magnification by two observers in millimeters.

The data were statistically analyzed using one-way ANOVA $(p<0.05)$, and Duncan's tests to determine statistical significant differences between groups. 


\section{RESULTS}

The positive control teeth showed complete dye penetration where as the negative control teeth showed no dye leakage.
The result of one way ANOVA test (Table1, Figure1) revealed that there was a significant difference among the three groups $(p<0.05)$.

Table (1): One way ANOVA Tests for The Apical Microleakage Among The experimentalGroups

\begin{tabular}{cccccc}
\hline & Degree of freedom & Sum of squares & Mean squares & F & Sig \\
\hline Betweengroups & 2 & 1.690 & 0.899 & 4.859 & 0.0179 \\
Within groups & 26 & 3.695 & 0.181 & & \\
Total & 28 & 5.385 & & & \\
\hline
\end{tabular}

Sig: significant at $(p<0.05)$

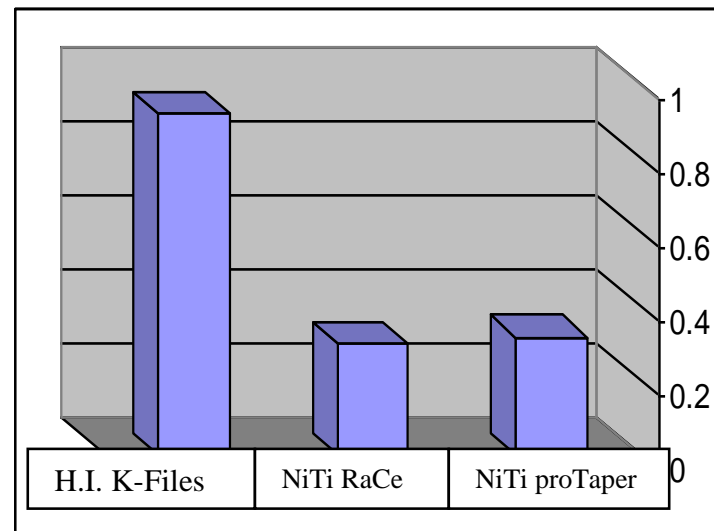

Figure (1):The Effect rotary Nickel-Titanium systems and hand instrumentation for root canal preparation on Microlekage.

Duncan's multiple range test (Table2) showed that group I and group II (ProtoTaper and $\mathrm{RaCe}$ ) represent the lowest mean of dye penetration (0.298), and the difference was statistically significant from the third group (hand instrument $\mathrm{K}$ files) which was showed more leakage mean $(0.921)$.

Table (2): Duncan's Multiple Range Testsfor The Experimental Groups

\begin{tabular}{clll}
\hline Group & Mean leakage $(\mathbf{m m})$ & Standard deviation & Duncan's group \\
\hline NiTi ProTaper & 0.319 & 0.299 & $\mathrm{~A}$ \\
NiTi RaCe & 0.298 & 0.327 & $\mathrm{~A}$ \\
Hand Instrument & 0.921 & 0.798 & $\mathrm{~B}^{*}$ \\
K-Files & & & \\
\hline
\end{tabular}

*Different letters mean significant differences.

The difference between the two groups (ProtoTaper and $\mathrm{RaCe}$ ) was not significant as shown in Figure (2).
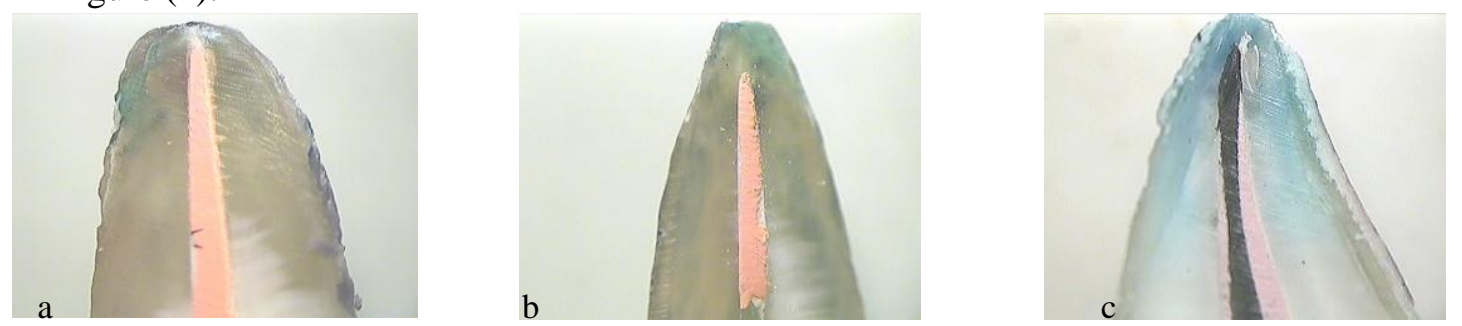

Figure (2): Microleage of different preparation techniques. (a) ProTaper (b) RaCe (C) Hand instrument K-files 


\section{DISCUSSION}

Chememechanical preparation is is a fundamental step during endodontic therapy because it combine with inter dependent factors the physical action of the instrument and chemical action of the irrigation solution. The aim of shaping and cleaning the root canals is to create ideal physiological and morphological obturation, providing recovery and regeneration of the periapical tissues. ${ }^{(14)}$ The efficacy of root canal obturation's sealibility greatly affects endodontic treatment. ${ }^{(15)}$ One of the most important objectives during root canal instrumentation is the removal of vital and/or necrotic pulp tissue, infected dentine, and dentin debris in order to eliminate most of the microorganisms from the root canal system. ${ }^{(16,17)}$

The use of light speed instrumentation with rotary instrument produced significantly cleaner canals than the hand $\mathrm{K}$ files. ${ }^{(18,19)}$ The root canal is a complex system with many surface irregularities, fins, accessory and lateral canal, and isthmuses. To seal this system, the filling must adapt to all portions of the root canal. Incomplete obturation of the canal system may result in the failure of the endodontic treatment. Root canal filling material are intended to prevent micro organisms and toxin in the canal from passing along the root canal space in to periradicular tissues. ${ }^{(20)}$

This study evaluated the effect of the use of three methods of root canal preparation (ProtoTaper, , $\mathrm{RaCe}$, and hand instrument K-files) on the apical microleakage with the use of methylene blue dye penetration technique.

For the prevention of apical leakage root canal fillings should provide a three dimensional apical and coronal sealing. ${ }^{(21)}$ However new materials and techniques are now available which may increase the potential for successful outcomes by creating a better adaptation between root canal walls and the filling material to decrease leakage. ${ }^{(22,23)}$

In this study the use of NiTi rotary instrument produces a well tapered root canal form sufficient for obturation, and completes preparation in an acceptable time on the other hand the manual techniques which takes more time without maintaining the canal curvature as well as NiTi system. This finding is in agreement with observation of (Thompson and Dummer) and that is due to grater flexibility of NiTi which has a superior ability to maintain curvature aven in severely curved root canals. ${ }^{(24,25)}$

Crown down technique which was used in this study by NiTi system is more effective in maintaining smooth surfaces than the manual techniques. ${ }^{(26)}$

Matched-taper gutta percha cone is more fit in the canal than lateral condensation which may leave microspace because the gutta percha dose not matching the canal wall. The superior sealing ability of the single cone Match-taper gutta percha due to it is ability to fit well along the root canal wall. ${ }^{(25,26)}$

Resin sealer (tagadseal) was chosen in this study because of it is low solubility in comparison with sealers like silicon, $\mathrm{Ca}(\mathrm{OH}) 2$, Zinc oxide euginol, and glassionomer GI based sealer. ${ }^{(27,28)}$

Root canal preparation by the use of manual technique K-files and lateral condensation technique has shown to form a non-homogenous mass of gutta-perch that poorly replicates the prepared root-canal space and does not adequately obturated simulated lateral canals. ${ }^{(20,27)}$

In this study there was no significant difference between the use of the two type of Ni-Ti rotary instrument which were the ProTaper and RaCe. Although manual technique group shown the more leakage than the first two group.

The use rotary instrument followed by the single-cone technique which consist of a single gutta-percha cone filled at room temperature with sealer layer thicknesses that vary depending on the adaptation of single cone to the walls of the canals. ${ }^{(29)}$ This method is simpler and faster than other obturation techniques and acceptable for filling canals, especially at the apical third $^{(30)}$.

With the widespread use of rotary NiTi instruments, matched-taper gutta-percha cones were developed and the single-cone technique has become popular. ${ }^{(31)}$

\section{CONCLUSION}

In the current study, the result of the 
use of rotary NiTi instruments with matched-tapered gutta-percha cones showed significantly less microleakage in term of linear dye penetration.

There are no significant differences between the Pro-Taper and the RaCe NiTi rotary instrument. Although the use of hand instrument $\mathrm{K}$-files showed more microleakage than the NiTi rotary instrument (Pro-Taper and $\mathrm{RaCe}$ ).

\section{REFERENCES}

1. Gibert SD, Witherspoon DE, Berry $\mathrm{CW}$. Coronal leakage following three obturation technique. Int Endod $J$. 2001; 34:293-9.

2. Monticelli F, Sword J, Martin RL, Schuster GS, Weller RN, Ferrari M, Pashley DH, Tay FR. Sealing properties of two contemporary single-cone obturation systems. Int Endod J. 2007; 40:374-85.

3. Yamauchi S, Shipper G, Bulke T, Yamauchi M, Trope M. Effect of orifice plugs on periapical inflammation in dogs. Int Endod J.2006; 32:524-6.

4. Gopkrishna V, Parames Waren A. Coronal sealing ability of three sectional obturation techniques simple fill, thermafil and warm vertical compaction compared with cold lateral condensation and post space preparation. Aust Endod J. 2006; 32:95-100.

5. Cobankara FK, Adanir N, Belli S, Phashley DH, A quantitative evaluation of apical leakage of four sealers. Int. Endo J. 2002; 35(12): 979-84.

6. Oksan T, Aktener BO, Sen BH, Tezel $\mathrm{H}$. The prepration of root canal sealers in to dentinal tubules scanning electron microscope study. Int. Endo J. 1993; 26: 301-5.

7. Chailertvanitkul P, Saunders WP, Saunders EM, Mackenzie D. An evaluation of microbial coronal leakage in the restored pulp chamber of root canal treated multi rooted teeth. Int Endod J. 1997; 30:318-22.

8. Walia HM, Brantley WA, Gerstein H, An initial investigation of the bending and torsional properties of NiTi root canal files. Int Endod J. 1988; 14(7): 346-51.

9. Schafer e, Vlassis M. Comparative in- vestigation of two rotary nickeltitanium instruments: ProtoTape versus $\mathrm{RaCe}$ part 1 . shaping ability in simulated canals. Int Endod J. 2004; 37(4):229-38.

10.Tasdemir Y, Aydemir H, Inan U, Unal O. Canal preparation with Hero 642 rotary Ni-Ti instruments compared with stainless steel hand K-files assessed using computed tomography. Int Endod J. 2005; 38(6): 402-8.

11.Ruddle CJ. The ProTaper technique Endodontic topics. 2005; 10:187-90.

12.Clauder T, Baumann MA, ProTaper NT system. Dent Clin North Am. 2004; 48(1): 87-111.

13. Noronha DE, Wagle R, Fernandes M. The quality of canal prepration using stainless steel hand files and nickeltetanium rotary instruments. Int Endodo J. 2005; 35:56-63.

14.Peters OA, Peters CL. Cleaning and shaping of the root canal system, In Cohen S, Hargreaves KM; Editors Pathways of the pulp. 9Th ed. St. Louis Mosby. Inc.2006; p:334-5.

15.Qualthrough AJ. Whitworth JM, Dummer PM. Preclinical endodontology an international compassion. Int Endod J. 1999; 32 (5): 406-14.

16. Vansan LP, Pecora JD, Costa WF, Maia Campos G. Effects of various irrigating solution on the root canal with ultrasonic instrumentation. Braz Dent $J$. 1990; (1): 37-44.

17. Namazikhah S, Shirani R, Mohseni A, Farsi OF. Dye leakage study: comparing conventional and new techniques. $J$ Calif Dent Assoc; 2000; 28:435-42.

18. American Association of endodontists (1998) Glossary. Con temporary terminology for endodontics. 6th ed AAE Chicago, II, USA.

19.European Society of endodontology (1994) consensus report of the European Society of endodontology on quality guideline for endodontic treatment. Int Endod J. 27, 115-24.

20.Tan BT, Messer HH. The quality of apical canal preparation using hand and rotary instruments with specific criteria for enlargement based on initial apical file size. J endodon. 2002; 28(9):658664.

21.Bodrumlu E, Tunga U. apical leakage 
of resilon obturation material. $J$ contemp Dent Pract. 2006; 45-52.

22. Haikel Y, Wittenmeyer W, Bateman G, Bentaleb A, Allemann C. A new method for the quantitative analysis od endodontic microleakage. Int Endodo J. 1999; 25: 172-177.

23. Short JA, Morgan LA, Baumgartiner JC. A comparsion of canal centering ability of four instrumentation techniques. Int. Endod J, 1997; 23:503-7.

24.Kandaswamy D, Venkate shabab N, Reddy G, Hannah R, Arthi G, Roohi R. Comparison of laterally condensed, vertically compacted thermoplasticized, cold free flow GP obturations. A volumetric analysis using spiral CT. $J$ conserve Dent. 2009;12(4):145-149.

25.Pettiette MT, Metzger Z, Phillips C, Trop M. Indodontic complications of root canal therapy performed by dental students with stainless-steel K-files and nickel titanium handfiles. Int Endod J. 1990; 25:230-4.

26.Tucker DM, Wenckus CS, Bentkover SK. Canal wall planning by enginedriven nickel-titanium instrument com- pared with stainless- steel hand instrumentation.

27. Brosco VH, Bernardineli N, Moraes IG. "In vitro" evaluation of the apical sealing of root canals obturated with different techniques. J Appl. Oral Sci. $2003 ; 11(3)$.

28. Scha E, and Zandbiglari T. Solubility of root canal sealers in water and artificial saliva. Int Endod J. 2003; 36(10): 660-9.

29.Zmener O, Pamerjar $\mathrm{CH}$, Macri E. Evaluation of the apical seal in root canals prepared with new rotary system and obturated with amethacrylate based endodontic sealer. An in vitro study. $J$ Endodo. 2005; 31(5): 392-5.

30.Gordon MP, Love RM. Ehandler NP. An evaluation of 0.06 tapered guttapercha cones for filling of 0.06 taper prepared curved root canals . Int Endod J. 2005; 38(2): 87-96.

31.Bal AS, Hicks ML, Barnett F. Comparison of laterally condensed 0.06 and 0.02 taperd gutta percha and sealer in vitro. Int Endodo J . 2001; 27(12): 7868 . 